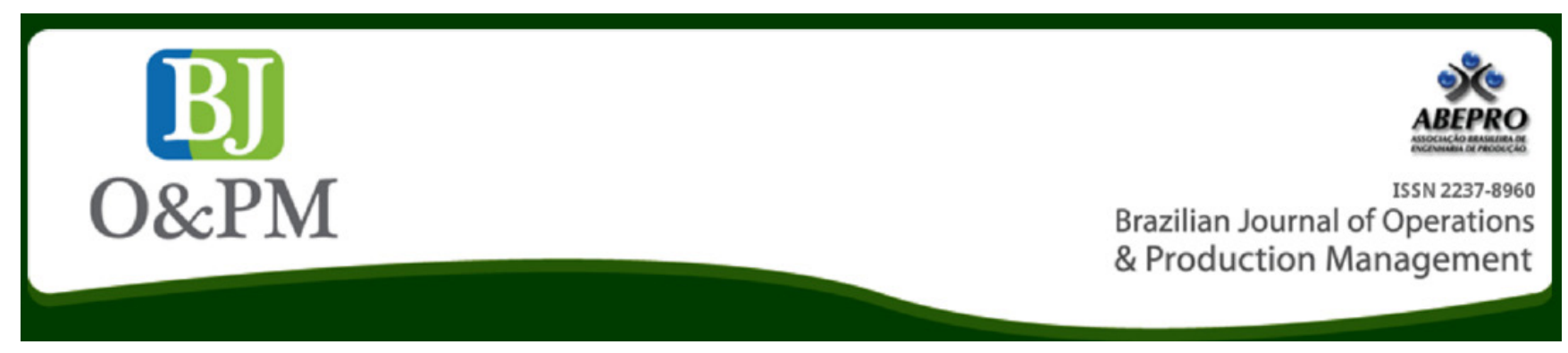

\title{
A REVIEW OF APPROACHES AND TOOLS FOR COLLABORATIVE NETWORKS SIMULATION
}

\author{
Beatriz Andres; Raul Poler $^{\mathrm{a}}$ \\ a Polytechnic University of Valencia (UPV) - Valencia, VC, Spain
}

\section{ABSTRACT}

Collaborative networks (CN) are characterised by being complex systems, highlighting the need of considering simulation approaches to support the resolution of $\mathrm{CN}$ models. Simulation approaches are seen as a supporting tool to analyse the formal model of a supply network. Three relevant simulation approaches are identified for its application in the context of CN models: Discrete Events Simulation, System Dynamics and Agent Based Simulation. Each simulation approach is briefly described and compared with each other, according to a group of relevant features, with the main aim of aiding the modellers in the task of selecting the most appropriate simulation approach to address the modelling process in the context of $\mathrm{CN}$. Besides, a group of commercial and academic tools are listed for each simulation approach.

Keywords: simulation approach, collaborative networks, discrete event, system dynamics, agent-based simulation 


\section{INTRODUCTION}

The study of complex systems has its origin in the study of Systems Theory. The number of applications of systems theory to organizations is very wide, and a high variety of system models have been developed. The first models were proposed by Barnard 1938, and were based on the notion of "balance". These models evolved towards the Sociological Systems Theory, defined by Selznick 1948, which introduced the analogy between the organisms and organizations. Subsequently, the General Systems Theory was presented, whose roots were found in the biology study area Bertalanffy 1950, which considered that the organisms are complex systems with rigorous operation of open systems. Bertalanffy 1968 as a biologist defined the systems as a set of interactive elements, and considered them as complex systems (i.e. multicellular organisms, ant colonies, ecosystems, economies, societies, enterprises, supply networks...) those characterized by having a structure composed of several levels. Afterwards, the Contingency Theory Kast and Rosenzweig 1981 and the Theory of Sociotechnical Systems Trist and Bamforth 1951 appeared. The Contingency Theory studies the organizations as sets of interdependent subsystems, each one carrying out its own functions to perform within the context of the organization. Due to the importance of the survival of any organization, each subsystem must be viable and effective and must be consistent with each other and with the environment into which it is embedded.

Complex systems are characterised by (i) its decentralized nature, in which the system behaviour arises from the self-organization of its components without these being controlled by any extrinsic entity to the system, (ii) the presence of loops of causality and nonlinear feedback, and (iii) the fact that it contains several self-contained units that can interact, evolve and adapt their behaviour to changes in the environment Vicsek 2002. Collaborative networks (CN) consist of a wide range of decentralised and heterogeneous entities each one carrying out different processes and activities to provide goods or services to final customers Camarinha-Matos and Afsarmanesh 2008. Furthermore, each organisation defines its own objectives and formulates its own strategies. This heterogeneity makes $\mathrm{CN}$ complex systems, involving that in most cases it would be very difficult to adequately model and solve them mathematically Izquierdo et al., 2008). Consequently, $\mathrm{CN}$ require the use of ad-hoc methodologies, models and tools to tackle problems and succeed in identifying proper and optimal solutions Castilla and Longo 2010. It is at this point where simulation approaches come into play.

In the light of this, this paper is organized as follows: Section 2 highlights the importance of relying on simulation approaches to solve complex systems. Three simulation approaches are described focusing on its application in $\mathrm{CN}$ : Discrete Event Simulation (DES), System Dynamics (SD) and Agent Based Simulation (ABS). These approaches are jointly compared in Section 3. In Section 4 an overview of the tools identified in each simulation approach is presented. Finally, the conclusions derived from the review are proposed in Section 5.

\section{COLLABORATIVE NETWORKS SIMULATION APPROACHES}

Concerning the supply network application area, simulation deals with (i) managing the complexity associated (as supply networks are considered complex systems), (ii) supporting the decision making process, and (iii) assessing the key factors (relevant performance measures) for the supply network, such as profits, customers' service or competitiveness. The construction of "WHAT-IF" scenarios, in supply network simulation approaches, will allow decision makers to obtain optimised solutions with less costs and time. Some examples can be found in terms of developing strategic plans based on market trends, company goals and competitors' strategies; creating adaptive operational management strategies that respond to internal and external dynamics such as demand fluctuations, change of suppliers, competitors' activities; or generating holistic plans considering strategic planning, marketing, and HR issues.

According to Shannon (1975), the construction of simulation-based models for supply networks are useful when:

- The supply network model to be simulated cannot be formulated in a mathematical notation.

- The supply network model can be mathematically formulated but there is no resolution method to solve the model.

- The supply network model can be expressed in a mathematical notation and there exist methods for its resolution, but these are costly, tedious and time consuming.

- The objective is to build experiments for comparing different scenarios of the supply network, and these experiments cannot be carried out in a real supply network.

Considering the literature reviewed, three are the main simulation approaches identified for its application in supply networks (Figure 1): Discrete Event Simulation (DES), System Dynamics (SD), and Agent Based Simulation (ABS). SD allows to model continuous process while $D E$ and $A B S$ are more used to model in discrete time. The level of abstraction is the other feature that differs from one simulation approach to another. Whereas SD allows representing models with 


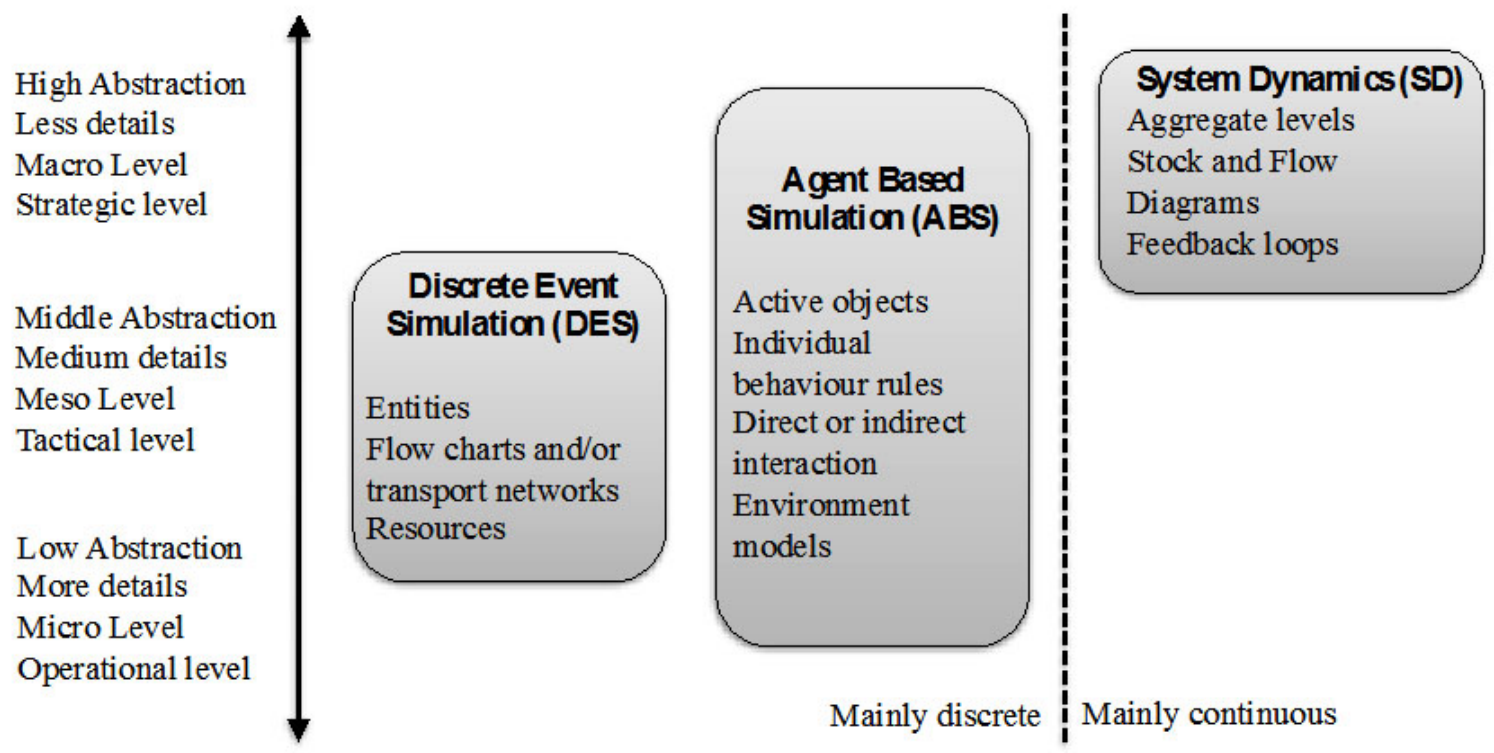

Figure 1. Simulation Approaches

Source: Adapted from Borshchev et Filippov (2004)

higher levels of abstraction and causal dependencies, ABS and DES considers higher levels of detail in the representation of individual entities/agents Tako et Robinson (2012). Figure 1 provides a graphical comparison of the three simulation approaches, which are analysed in this chapter with the main aim of dealing with supply network simulation-based models.

In the next subsections a brief definition is given for each simulation approach, previously identified.

\subsection{Discrete Events Simulation}

DES simulation approach has its origin in the evolution of the General Purpose Simulation System (GPSS) (originally Gordon's Programmable Simulation System) proposed by Gordon (1961). DES simulation approach considers individual entities, each one with specific attributes, which determine their behaviour along the simulation process Tako et Robinson (2012). DES is based on the concept of entities (seen as passive objects representing people, machines, messages, tasks, etc.), resources and block flow charts, through which the entities pass and stay in queues, are delayed or are processed Borshchev et Filippov (2004). This means that entities enter the system, visit some of the states and move between different states as time passes, after that the entities leave the system Siebers et al., 2010. DES plays a significant role in modelling supply networks, especially at the tactical level. As DES does not represent systems from an aggregate perspective, it is not appropriate for strategic modelling. Works worth to mention in the context of supply networks are those developed by Lee et al., (2002) and Kleijnen et Wan (2007).
One characteristic of DES is that it includes stochastic elements through the use of statistical distributions, when randomness is generated, Kleijnen, 2005. DES state changes occur at irregular discrete points of time, such as network of queues.

The drawbacks associated to DES simulation paradigm in the context of supply networks are the (i) lack of representation of continuous processes, and (ii) the higher complexity obtained due to DES represent high detailed models Lee et al., 2002.

During the seventies DES was solely used in the research field. It was changed in the nineties when software applications were developed for simulating the complex queuing theory and resource allocation problems. The acceptance of DES as a management tool was triggered by the development of well know software tools, such as Kelton, Sadowski, et Sturrock (2003).

\subsection{System Dynamics}

Forrester is considered the precursor of System Dynamics (SD), which has its starting point in the Industrial Dynamics Forrester (1961). The Industrial Dynamics has its origins in a study carried out in a company of electronic components, Sprague Electric, as a new approach to address industrial problems. The main trouble found in this company was the appearance of oscillations in the order process. These oscillations were considered unusual due to the nature of the market in which Sprague Electric was embedded. That is, a market consisting of a few strong customers, from which it would expect that the orders' flow would be 
maintained regular. Unlike, in the mid 50's, it was observed that the orders generated were characterised by suffering oscillations.

According to this, Forrester, who was teaching at the newly formed M.I.T. Sloan School of Management, started to study this phenomenon. In the study, Forrester identified as key issue, in the operation of process, the feedback presented in the information structures. This finding involved an intelligent application of the theory of feedback systems; allowing representing the elements of the system, and their relations, by identifying the feedbacks to justify the appearance of oscillations. This representation enabled to identify and take the necessary measures to correct the existent oscillations in Sprague Electric. In the late fifties, and from the results of the performed work, Forrester formalized his ideas and methodology, resulting in the Industrial Dynamics methodology. Industrial Dynamics included structural aspects such as feedback control, and represented a new approach to address industrial problems, based on the analysis of the internal structure of the systems rather than the impact of exogenous factors affecting it.

Once the Industrial Dynamics method reached an acceptable level of maturity, the same concept was extended to social systems. Urban Dynamics was created in Forrester, (1969) as a result from his collaboration with John Collins, the former mayor of Boston and visiting professor of Urban Affairs at Massachusetts Institute of Technology (M.I.T.).

In 1970, Forrester was invited by the Club of Rome to apply his methodology in the study of the world, considering it as a dynamic system. The result was the Model of the World Forrester (1971). The application of industrial dynamics at urban and worldwide context triggered to rename the Industrial Dynamics methodology into a broader term, currently known as System Dynamics Forrester (1968).

The SD is based on the feedback control theory, decision-making processes, experimental approaches and computational developments Campuzano et Mula, (2011). Forrester developed the SD method as a set of tools and an approach to simulate complex systems, such as the supply network. Through SD it was possible to understand the structure of a system and identify how the intrinsic control policies operate. The supporting tools associated to SD enabled to improve the system assessment by simulating its behaviour.

Since its appearance, SD has been widely studied and disseminated in multiple research areas. Its application in case studies can be seen in areas such as defence Cooper, ( 1980)social sciences Richardson (1991), medical science Homer (1987), ecology Sterman, Richardson, et Davidsen, (1998), ecosystem Wang et Eltahir (2000), natural resources management, project management Lyneis et Ford (2007), social Lane et Husemann, 2008, socioeconomic systems and transportation Liu, Triantis, et Sarangi, 2010, civil construction Lee et Peña-Mora (2007), strategy management Weil (2007) Gary, Kunc, et Morecroft, 2009, management Roberts (1978), knowledge sharing Luna-Reyes et al., 2008, resource allocation Lee, Ford, et Joglekar, 2007, disruptions (Williams, Ackermann, et Eden, 2003 or supply networks Ashayeri, Keij, et Bröker (1998) Campuzano, Mula, et Peidro (2010).

SD allows building (i) models based on previous situations faced by decision makers in the supply network, by considering their experience; (ii) dynamic models appearing on reality that are able to self-regulate their activities through feedback loops, applying the feedback systems theory; (iii) models using the computer as a supporting tool, allowing to compute models through simulating different scenarios in a short time and at low cost.

SD dissemination is done through the publication of papers in journals such as System Dynamics Review and other journals in management, operations research and social sciences. Besides, different groups worldwide, employing system dynamics, are also spreading the SD method, one referent group is the System Dynamics Group at MIT.

\subsection{Agent Based Simulation}

ABS approach was developed in the nineties as a novel tool to deal with problems that were not completely satisfactorily solved through using DES and SD. For example, in the operation research area, high complex management process and global and dynamic environments, in which enterprises are embedded, makes that traditional simulation approaches, such as DE, present limitations as a supporting tool to model and simulate complex systems North et Macal (2007). It is, therefore, recognised the high potential application linked to ABS for modelling and simulating complex systems Siebers et al., 2010performing a new step in the progress of simulation methods, and in the enhancement of simulation applications.

According to Siebers et al., (2010) ABS approach is used in the process of designing an agent-based model of a real system. ABS allows carrying out experiments with the agent-based model for the purpose of understanding the behaviour of the system and/or evaluating various strategies for the operation of the system being modelled. ABS allows representing complex systems through the use of a collection of agents that are programmed according to a set of behaviour rules and objectives, which enables them to have control over themselves and make their own decisions.

In agent-based models, the basic components of the real system are explicitly and individually represented in the model Edmonds (2002) . ABS systems are characterized by comprising multiple autonomous, heterogeneous and 
Brazilian Journal of Operations \& Production Management

Volume 13, Número 3, 2016, pp. 232-242

DOI: 10.14488/BJOPM.2016.v13.n3.a1 independent agents, each one with their own objectives, and are generally capable to interact with each other and with their environment. Therefore, interactions established between the individual agents and the environment are also modelled. Each agent has the capacity to evolve over the time and adapt to new environmental conditions or objectives. One of the fundamental points of agent-based simulation is the concept of emergence. The agents' behaviour is modelled at the individual level, and the global behaviour emerges as a result of the interactions with many individuals, each one following its own behaviours and rules. Neither the expert nor the modeller imposes conditions on the overall behaviour of the system directly, due to it emerges as a result of the conditions imposed on the basic system components and their interactions. That is why ABS modelling is also called bottom-up modelling, corresponding to the macroscopic patterns that emerge from the decentralised interactions of simpler individual components Holland (1998). This bottom-up approach allows capturing the complexity and dynamicity of the modelled system. In ABS interactions between the basic components of the system are studied, therefore the system can be modelled even in the absence of the knowledge about the global interdependencies Izquierdo et al., 2008)).

ABS approach is a powerful technique for modelling complex systems, such as social systems Gilbert (2007), health Brailsford et al., 1992 traffic and transportation, financial markets, energy usage North et Macal, 2007 or supply networks Hernández et al., 2009. Generally, ABS allows analysing the behaviours of real systems that consist of autonomous entities.

It is well known that depending on the type of modelled problem and its characteristics, the simulation approaches used to model and solve them will differ. In some situations, ABS will fit better the modelling requirements due to its flexibility and robustness; nevertheless for some other approaches DES and SD will be useful. In accordance to Siebers et al., 2010 ABS are recommended when:

- $\quad$ The problem to be modelled has a natural representation as agents

- $\quad$ The goal is to model the behaviours of individuals in a diverse population

- $\quad$ Agents are related each other (social networks)

- Individual agents have associated movements in the space

- Agents to be modelled in the population have to learn or adapt

- Agents anticipate other agents' reactions when making decisions

- $\quad$ Represent collaborative behaviours
- The past is not used as a predictor of the future

- It is important to extend models in the future

- The emergence feature is a key issue in the problem modelled

\section{SIMULATION APPROACHES COMPARISON}

In order to select one or another simulation approach for modelling complex systems (supply networks), the literature brings some works making pairwise comparisons. The characteristics of DES approaches are mostly compared with the SD ones Maidstone (2012) Tako et Robinson (2012). Some authors focus on contrasting the usability and application between SD and ABS Borshchev and Filippov (2004), Izquierdo et al., 2008, Macal (2010), Maidstone (2012). While others analyse DES paradigm versus ABS approaches Borshchev et Filippov (2004) Siebers et al., 2010 Maidstone (2012). The work presented in Sumari et al.,(2013) proposes a initial work comparing the three simulation approaches DES, SD and ABS but by only considering the disadvantages, the advantages and the tools (focusing in Promodel, Vensim, and AnyLogic) that can be used in each simulation method. In this area a more comprehensive research is needed to jointly compare the three simulation approaches by considering more features such as the appropriate usage, the decision making level in which there can be applied, the degree of centralisation the level of abstraction, the complexity, components used, the entities behaviour, the modelling approach, the mathematical approximation, the evolution over the time, the data requirement, the validation requirements and the application into the SC context .

In the light of this, Table 1 intends to give an overall comparison of the same features for the three simulation approaches, DES, SD and ABS. Derived from the comparative work it can be concluded that the differences among the compared approaches are sometimes not so clear-cut. In this regard, Macal (2010) states that most of the models build in SD have an equivalent formulation in ABS approaches.

As a general recommendation, the choice of one or the other simulation approach depends on the perspective from which the modeller views the problem and the features that characterises the system, which, in fact, define the requirements of the modelled complex system. Besides, the modellers' familiarity with the software used must be considered in the selection of the simulation approach.

The research carried out to build the comparison work has allowed identifying how common is to combine different simulation approaches in order to model more accurately an only complex system. This definition corresponds to the term multi-method approach of simulation that according to Balaban et Hester (2013)resolution, and fidelity consist of 


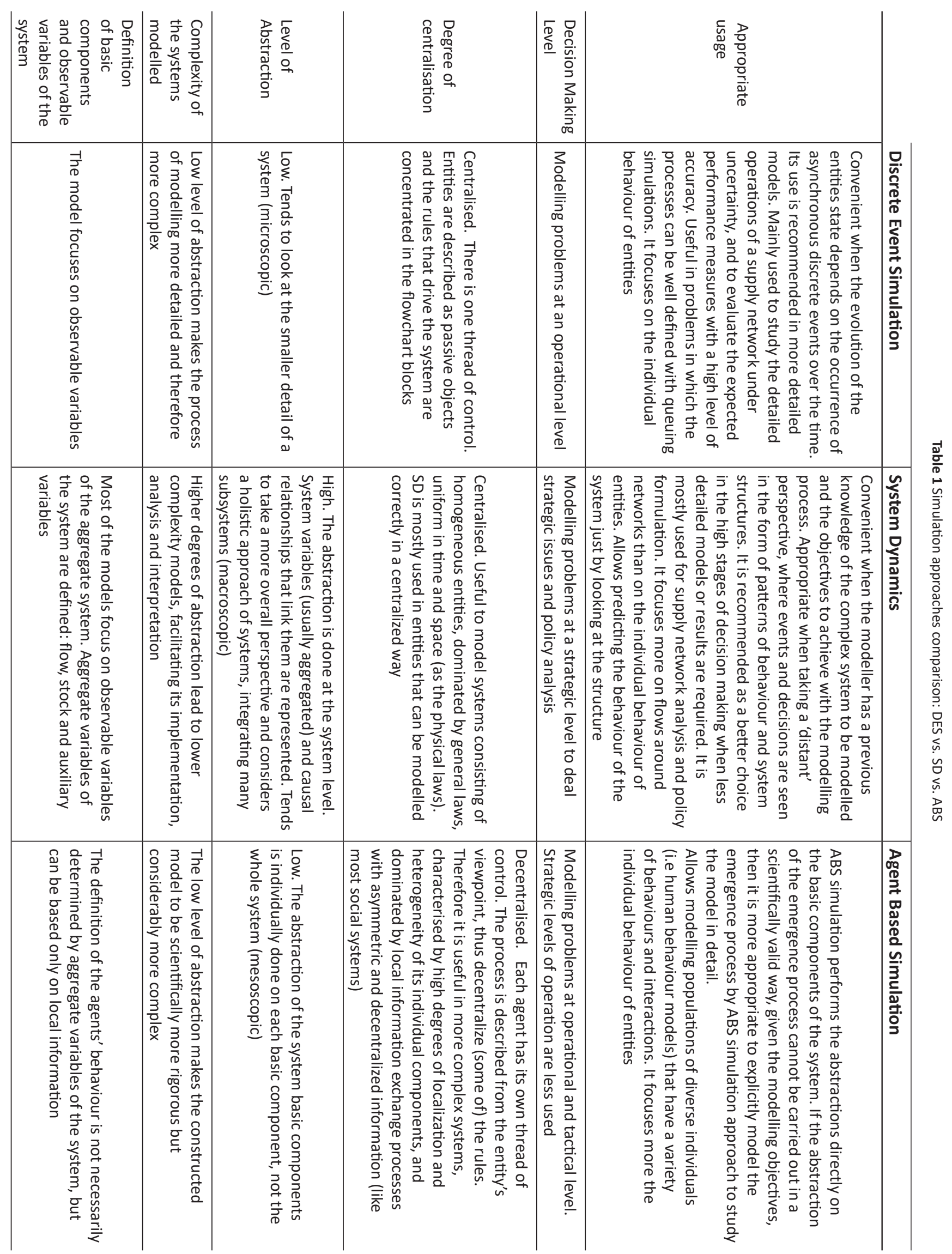




\begin{tabular}{|c|c|c|c|c|c|c|c|}
\hline & 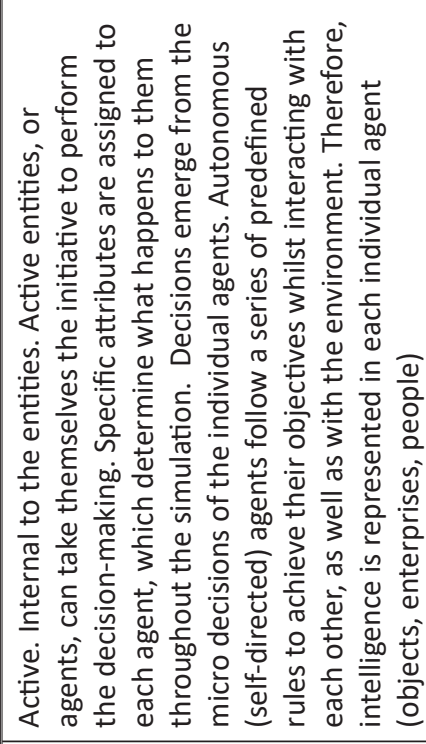 & 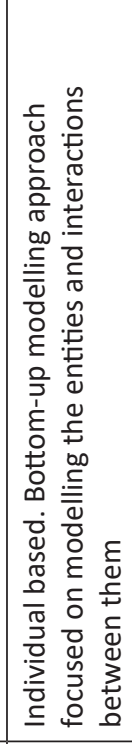 & 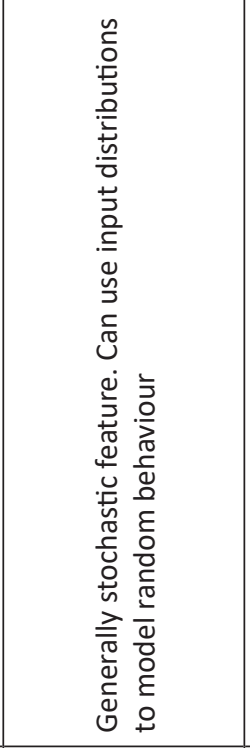 & 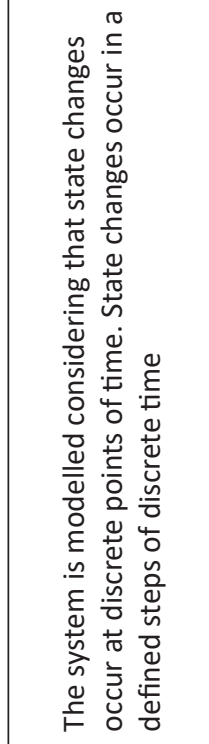 & 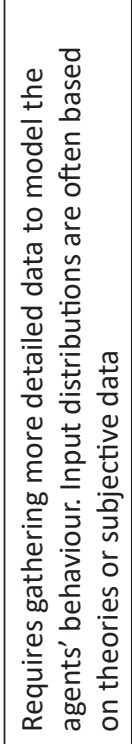 & 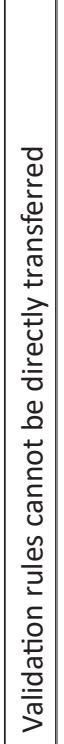 & 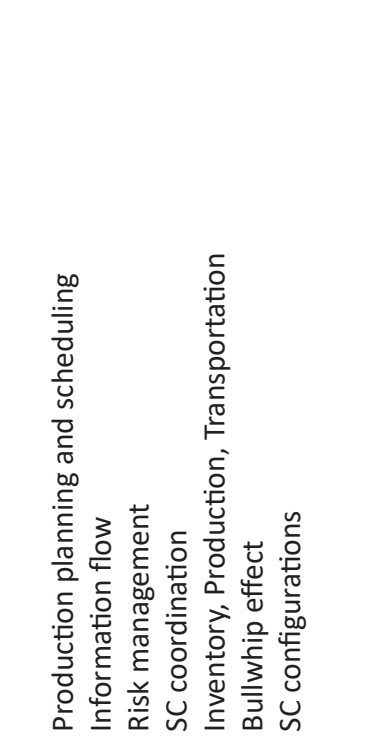 \\
\hline & 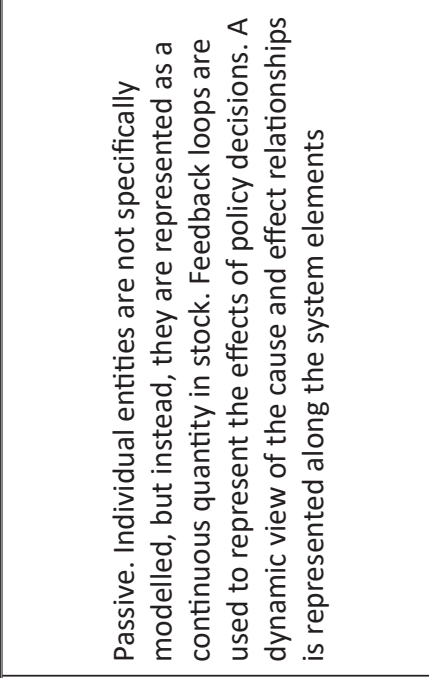 & 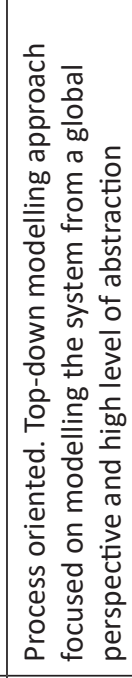 & 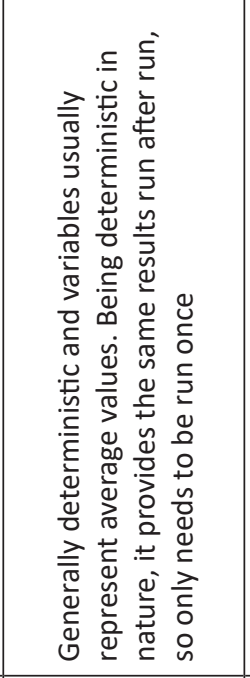 & 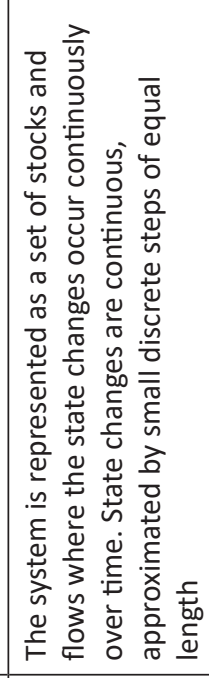 & 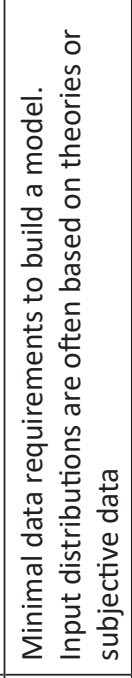 & 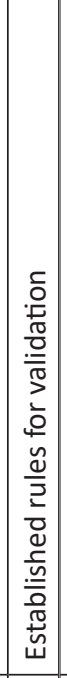 & 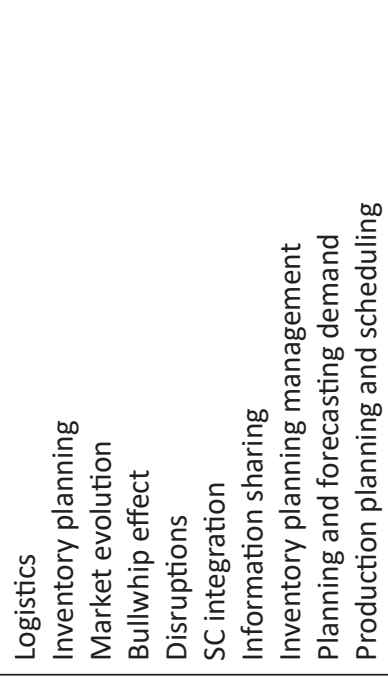 \\
\hline \multirow[t]{2}{*}{ 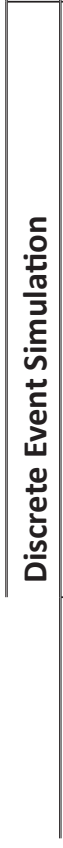 } & 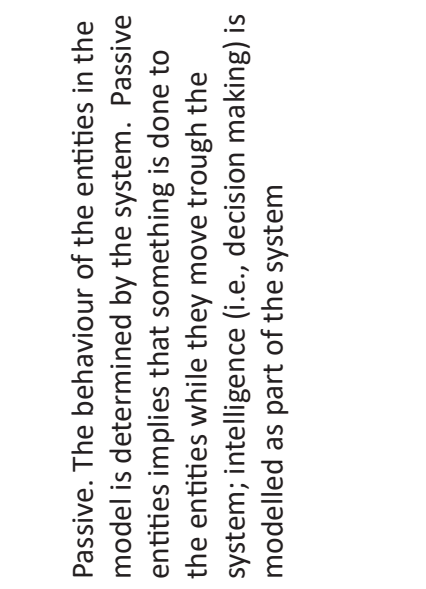 & 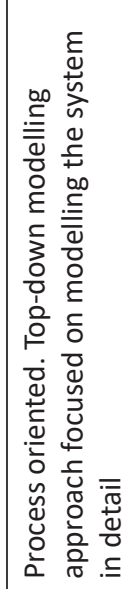 & 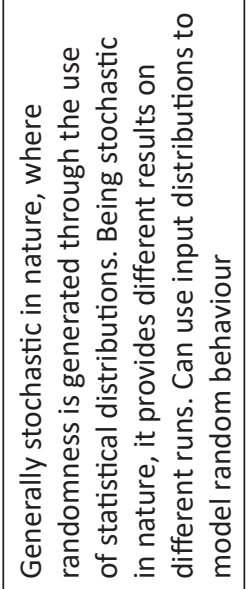 & 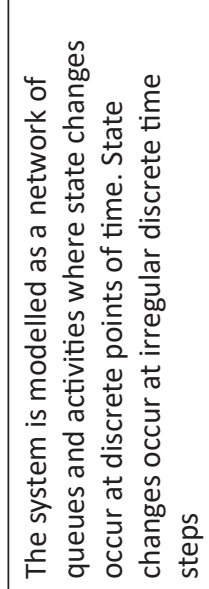 & 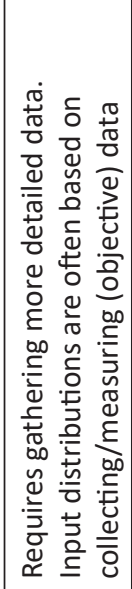 & 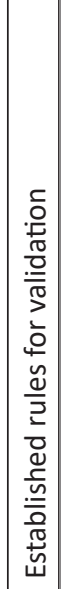 & 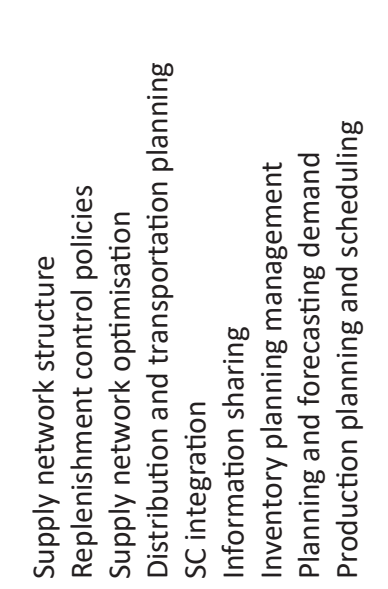 \\
\hline & 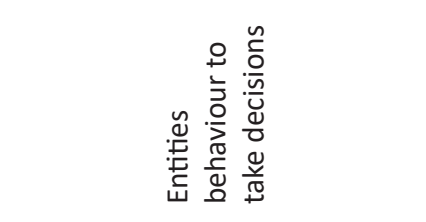 & 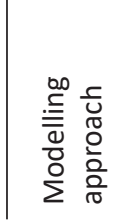 & 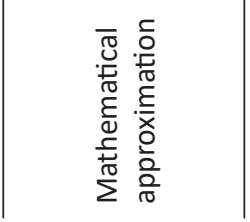 & 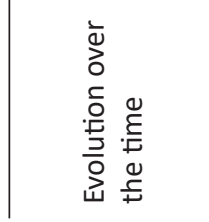 & 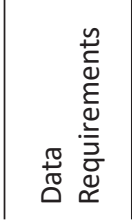 & 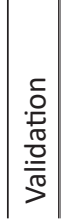 & 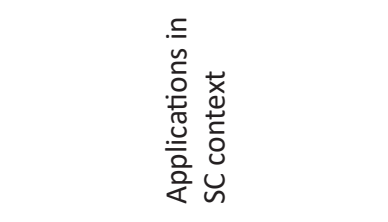 \\
\hline
\end{tabular}


a combination of at least two different simulation approaches representing and modelling a unique system. The types of combinations are about:

- Combination of SD and ABS. Development of models in which a group of agents individually and explicitly represented interact in an environment in which certain variables evolve following a dynamic approach. The combination of both simulation approaches, SD and ABS will allow to enhance the ABS model, capturing more sophisticated dynamics Borshchev et Filippov (2004).

- Combination of SD and DES. In the context of representing the system of an integrated enterprise DES can be used to model local production planning or sequencing activities while SD can capture the long term effects caused by the disruptions or delays in production planning Rabelo et al., 2005

- Combination of DES and ABS. The process flow is modelled from a DES perspective and autonomous active entities in ABS approach (replacing passive entities modelled in $\mathrm{DE}$ ), with the main aim of displaying proactive behaviours Siebers et al., 2010.

\section{SIMULATION TOOLS}

This section gives a brief overview of the tools, and its characteristics, identified in each simulation approach (Table 2). In Table 3, a list of tools - alphabetically ordered is depicted for each simulation approach.

Most of the tools are characterised its specific use in a particular simulation approach. Nevertheless, AnyLogic (AnyLogic, 2015) commercial tool is characterised by offering a multi-method approach in which the three simulation paradigms can be represented in the same visual environment. It allows modelling different parts of an only model with different simulation approaches. The main disadvantage that modellers have to overcome using AnyLogic is related to their familiarity to work in Java environments.

Table 2. Comparison of tools characteristics of the studied simulation approaches

\begin{tabular}{|c|c|c|c|}
\hline & Discrete Event Simulation & System Dynamics & Agent Based Simulation \\
\hline $\begin{array}{l}\text { Tools } \\
\text { Availability } \\
\text { and } \\
\text { Software }\end{array}$ & $\begin{array}{l}\text { High software maturity. The } \\
\text { scientific community has } \\
\text { experience on the software. } \\
\text { Increasing computer power and } \\
\text { evolving user interfaces led the } \\
\text { DES software to progressively } \\
\text { move towards 'drag and drop'. } \\
\text { Languages, such as the Simul8, } \\
\text { emerged to make the DES } \\
\text { accessible and cost effective for all } \\
\text { business sizes. Management tools } \\
\text { are really applied }\end{array}$ & $\begin{array}{l}\text { High software maturity. The process } \\
\text { of designing a SD model is simpler, } \\
\text { partly because formal models are } \\
\text { usually less complex, and partly } \\
\text { due to the availability of software } \\
\text { tools at very high level. The ease of } \\
\text { construction and analysis of system } \\
\text { dynamics models using "drag and } \\
\text { drop" tools has been one of the } \\
\text { main reasons for its popularity in } \\
\text { the scientific community }\end{array}$ & $\begin{array}{l}\text { Low software maturity. The } \\
\text { scientific community is less } \\
\text { familiar with software. Tools use } \\
\text { object-oriented programming } \\
\text { languages (i.e. Java, } \mathrm{C}++ \text { ) allowing } \\
\text { extensibility to model more } \\
\text { agents and behaviours. Software } \\
\text { is more focused to academic. } \\
\text { Software is too technical for mass } \\
\text { adoption and difficult to integrate } \\
\text { into teaching }\end{array}$ \\
\hline
\end{tabular}


Table 3. Simulation Approaches Tools

\begin{tabular}{|c|c|c|c|c|c|}
\hline $\begin{array}{l}\text { Discrete Event } \\
\text { Simulation }\end{array}$ & $\begin{array}{l}\text { System } \\
\text { Dynamics }\end{array}$ & & Agent B & sed Simulation & \\
\hline $\begin{array}{l}\text { adevs } \\
\text { AnyLogic } \\
\text { Arena } \\
\text { CPN Tools } \\
\text { DESMO-J } \\
\text { Enterprise } \\
\text { Dynamics } \\
\text { ExtendSim } \\
\text { Facsimile } \\
\text { Flexim } \\
\text { Galatea } \\
\text { GoldSim } \\
\text { Lanner L-SIM } \\
\text { Server } \\
\text { MASON } \\
\text { MS4 Modeling } \\
\text { Environemnt } \\
\text { NetSim } \\
\text { PlantSimulation } \\
\text { PowerDEVS } \\
\text { ProModel } \\
\text { Ptolemy II } \\
\text { Renque } \\
\text { Sim Events } \\
\text { SIM.JS } \\
\text { Simcad Pro } \\
\text { SimPy } \\
\text { SIMUL8 } \\
\text { SystemC } \\
\text { Tortuga } \\
\text { Vanguard } \\
\text { Witness }\end{array}$ & $\begin{array}{l}\text { Analytica } \\
\text { AnyLogic } \\
\text { ASCEND } \\
\text { Consideo } \\
\text { DYNAMO } \\
\text { Dynaplan Smia } \\
\text { Forio } \\
\text { Simulations } \\
\text { Insight Maker } \\
\text { JDynSim } \\
\text { MapleSim } \\
\text { Mapsim } \\
\text { Minsky } \\
\text { NetLogo } \\
\text { OptiSim } \\
\text { Powersim Studio } \\
\text { Pyndamics } \\
\text { RecurDyn } \\
\text { Simantics } \\
\text { System } \\
\text { Dynamics } \\
\text { Simile } \\
\text { Simulink } \\
\text { Sphinx SD Tools } \\
\text { Stella, iThink } \\
\text { Sysdea } \\
\text { SystemDynamics } \\
\text { TRUE (Temporal } \\
\text { Reasoning } \\
\text { Universal } \\
\text { Elaboration) } \\
\text { Vensim } \\
\text { VisSim }\end{array}$ & $\begin{array}{l}\text { A3 / AAA (Agent } \\
\text { Anytime Anywhere) } \\
\text { ABLE (Agent Building } \\
\text { and Learning } \\
\text { Environment) } \\
\text { Altreva Adaptive } \\
\text { Modeler } \\
\text { ADK (TryllianAgent } \\
\text { Development Kit) } \\
\text { AgentBuilder } \\
\text { AgentSheets } \\
\text { AnyLogic } \\
\text { AOR Simulation } \\
\text { AgentService } \\
\text { Ascape } \\
\text { Behaviour } \\
\text { Composer (Rich } \\
\text { Internet Application } \\
\text { building on NetLogo) } \\
\text { Brahms } \\
\text { Breve } \\
\text { Boris } \\
\text { Construct } \\
\text { Cormas(Common- } \\
\text { pool Resources } \\
\text { and Multi-Agent } \\
\text { Systems) } \\
\text { Cougaar } \\
\text { CybelePro } \\
\text { DALI } \\
\text { DeX } \\
\text { DigiHive } \\
\text { D-OMAR(Distributed } \\
\text { Operator Model } \\
\text { Architecture) } \\
\text { ECHO }\end{array}$ & $\begin{array}{l}\text { ECJ } \\
\text { FAMOJA(Framework } \\
\text { for Agent-based } \\
\text { MOdelling with } \\
\text { JAva) } \\
\text { Framsticks } \\
\text { FLAME } \\
\text { FLAME GPU } \\
\text { FLUXY } \\
\text { GAMA } \\
\text { GPU Agents } \\
\text { GROWlab } \\
\text { iGen } \\
\text { ICARO-T } \\
\text { Insight Maker } \\
\text { JABM } \\
\text { JADE } \\
\text { JAMEL (Java } \\
\text { Agent-based } \\
\text { MacroEconomic } \\
\text { Laboratory) } \\
\text { Janus } \\
\text { JAS } \\
\text { JASA (Java Auction } \\
\text { Simulator API) } \\
\text { Jason } \\
\text { (Jason:Interpreter } \\
\text { for extension of } \\
\text { AgentSpeak) } \\
\text { JCA-Sim } \\
\text { jES (Java Enterprise } \\
\text { Simulator) } \\
\text { jEcho } \\
\text { JESS } \\
\text { LSD (Laboratory } \\
\text { for Simulation } \\
\text { Development) } \\
\text { JA }\end{array}$ & $\begin{array}{l}\text { MaDKit (Multi Agent } \\
\text { Development Kit) } \\
\text { MAGSY } \\
\text { MAML (Multi-Agent Modeling } \\
\text { Language) } \\
\text { MASON } \\
\text { MASS (Multi-Agent Simulation } \\
\text { Suit) } \\
\text { MAS-SOC (Multi-Agent } \\
\text { Simulations for the SOCial } \\
\text { Sciences) } \\
\text { MIMOSE (Micro-und } \\
\text { Multilevel Modelling } \\
\text { Software) } \\
\text { Moduleco } \\
\text { MOOSE(Multimodeling } \\
\text { Object-Oriented Simulation } \\
\text { Environment) } \\
\text { NetLogo } \\
\text { OBEUS (Object Based } \\
\text { Environment for Urban } \\
\text { Simulation) } \\
\text { Omonia(previouslyQuicksilver) } \\
\text { oRIS } \\
\text { PS-I (Political Science-Identity) } \\
\text { Repast } \\
\text { SDML (Strictly Declarative } \\
\text { Modeling Language) } \\
\text { SEAS (System Effectiveness } \\
\text { Analysis Simulation) }\end{array}$ & $\begin{array}{l}\text { SeSAm (Shell } \\
\text { for Simulated } \\
\text { Agent Systems) } \\
\text { (fully integrated } \\
\text { graphical } \\
\text { simulation } \\
\text { environment) } \\
\text { Jade's sim++ } \\
\text { JIAC } \\
\text { SimPlusPlus } \\
\text { SimAgent (alsosim } \\
\text { agent) } \\
\text { SimBioSys } \\
\text { SimPack } \\
\text { Spatial Modeling } \\
\text { Environment(SME) } \\
\text { Soar } \\
\text { StarLogo } \\
\text { MacStarLogo } \\
\text { OpenStarLogo } \\
\text { StarLogoT } \\
\text { StarLogo TNG } \\
\text { Sugarscape } \\
\text { Swarm } \\
\text { TerraME } \\
\text { VisualBots } \\
\text { VSEit } \\
\text { Xholon } \\
\text { ZEUS }\end{array}$ \\
\hline
\end{tabular}

\section{CONCLUSIONS}

The aim of this paper is to discuss the use of different simulation approaches to support the modelling and resolution process of complex systems, such as the $\mathrm{CN}$. Three simulation approaches are considered as relevant to the scope of our purpose: DES, SD and ABS each one with its advantages and disadvantages for modelling the $\mathrm{CN}$. It has been considered that depending on the characteristics of problem/process to be modelled and the availability of the tools in which the simulation approach is supported, one approach or another will be selected. Moreover, the modellers' familiarity with the used software must be considered.

To sum up, DES is recommended to be used for the study of supply network process characterised by being under uncertainty conditions, or collaborative process that can be modelled with queuing simulations, in which the state of the model elements evolves according to discrete events behaviour. SD can be usefully applied in complex systems in which models are represented with less detail in order to predict the behaviour, given certain initial conditions. In SD the processes can be represented from a continuous perspective. Finally, ABS has its application in systems in which the elements that take part are sufficient autonomous to perform themselves the decision-making process.

Focusing on the available tools, AnyLogic (AnyLogic 2015) simulation software must be highlighted due to the multidisciplinary offered enabling to use the same tool to simulate in the three simulation approaches. 
Brazilian Journal of Operations \& Production Management

Volume 13, Número 3, 2016, pp. 232-242 DOI: 10.14488/BJOPM.2016.v13.n3.a1

\section{REFERENCES}

AnyLogic (2015), "AnyLogic." Retrieved (http://www.anylogic.com/).

Ashayeri, J., R. Keij, and A. Bröker (1998), "Global Business Process Re-Engineering: A System Dynamics-Based Approach." International Journal of Operations \& Production Management 18(9/19):817-31.

Balaban, M., and P. Hester (2013), "Exploration of Purpose for Multi-Method Simulation in the Context of Social Phenomena Representation." Pp. 1661-72 in Proceedings of the 2013 Winter Simulation Conference, edited by R Pasupathy, S.-H. Kim, A Tolk, R Hill, and M E Kuhl.

Barnard, C. (1938), The Functions of the Executive. Hardvard University Press, Cambridge.

Bertalanffy, L. (1950), The Theory of Open Systems in Physics and Biology. Systems thinking.

Bertalanffy, L. (1968), General System Theory. New York: George Braziller.

Borshchev, A., and A. Filippov (2004), "From System Dynamics and Discrete Event to Practical Agent Based Modeling: Reasons, Techniques, Tools." in The 22nd International Conference of the System Dynamics Society. July 25 - 29, 2004, Oxford, England.

Brailsford, S. C., A. K. Shahani, R. Basu, and S. Sivapalan (1992), "Simulation Modelling for HIV Infection and AIDS." International Journal of BioMedical Computing 31(2):73-88.

Camarinha-Matos, L. M., and H. Afsarmanesh (2008), Collaborative Networks: Reference Modelling. Springer International Publishing.

Campuzano, F., and J. Mula (2011), Supply Chain SimuIation. A System Dynamics Approach for Improving Performance. Springer London Dordrecht Heidelberg New York.

Campuzano, F., J. Mula, and D. Peidro (2010), "Fuzzy Estimations and System Dynamics for Improving Supply Chains." Fuzzy Sets and Systems 161(11):1530-42. Retrieved (http:// linkinghub.elsevier.com/retrieve/pii/S0165011409005296).

Castilla, I., and F. Longo (2010), "Modelling and Simulation Methodologies, Techniques and Applications: A State of the Art Overview." International Journal of Simulation \& Process Modelling 6(1):1-6.

Cooper, K. G. (1980), “Naval Ship Production: A Claim Settled and a Framework Built." Interfaces 10(6):20-36.

Edmonds, B. (2002), "The Use of Models - Making MABS More Informative." Pp. 15-32 in Multi-Agent-Based Simulation. Lecture Notes in Computer Science. Berlin: SpringerVerlag.
Forrester, J. W. (1961), Industrial Dynamics. Cambridge, MA: MIT press.

Forrester, J. W. (1968), Principles of Systems. Wright-Allen Press.

Forrester, J. W. (1969), Urban Dynamics. Pegasus Communications.

Forrester, J. W. (1971), World Dynamics. Wright-Allen Press.

Gary, M. S., M. Kunc, and D. W. Morecroft. (2009), "System Dynamics and Strategy." System Dynamics Review 24(4):407-29.

Gilbert, N. (2007), Agent-Based Models. Quantitative Applications in the Social Sciences. London: SAGE Publications.

Gordon, G. (1961), “A General Purpose Systems Simulation Program." Pp. 87-104 in Proceedings of EJCC, edited by McMillan NY. Washington D.C.

Hernández, J. E., M. M. E. Alemany, F. C. Lario, and R. Poler (2009), "SCAMM - CPA : A Supply Chain Agent - Based Modelling Methodology That Supports a Collaborative Planning Process." Innovar 19(34):99-120.

Homer, J. B. (1987), “A Diffusion Model with Application to Evolving Medical Technologies. ," Technological Forecasting and Social Change 31(3):197-218.

Izquierdo, L. R., J. M. Galán, J. I. Santos, and R. Olmo (2008), "Modelado de Sistemas Complejos Mediante Simulación Basada En Agentes Y Mediante Dinámica de Sistemas." Revista de Metodologia de Ciencias Sociales 16(16):85-112. Retrieved (http://e-spacio.uned.es/revistasuned/index. php/empiria/article/view/1391).

Kast, F. E., and J. E. Rosenzweig (1981), Organization and Management: A System and Constingency Approach. McGraw Hill.

Kelton, W. D., R. P. Sadowski, and D. T. Sturrock (2003), Simulation with Arena. McGraw-Hill: New York.

Kleijnen, J. P. C. (2005), "Supply Chain Simulation Tools and Techniques: A Survey." International Journal of Simulation and Process Modelling 1(1-2):82-89.

Kleijnen, J. P. C., and J. Wan (2007), "Optimization of Simulated Systems: OptQuest and Alternatives." Simulation Modelling Practice and Theory 15(3):354-62. Retrieved (http:// linkinghub.elsevier.com/retrieve/pii/S1569190X06000931).

Lane, D. C., and E. Husemann (2008), "Steering without Circe: Attending to Reinforcing Loops in Social Systems." System Dynamics Review 24(2):37-61.

Lee, S. H., and F. Peña-Mora (2007), "Understanding and Managing Iterative Error and Change Cycles in Construction." 
Brazilian Journal of Operations \& Production Management

Volume 13, Número 3, 2016, pp. 232-242

DOI: 10.14488/BJOPM.2016.v13.n3.a1

System Dynamics Review 23(1):35-60. Retrieved (http://doi. wiley.com/10.1002/sdr.359).

Lee, Y. H., M. K. Cho, S. J. Kim, and Y. B. Kim (2002), "Supply Chain Simulation with Discrete-continuous Combined Modeling." Computers \& Industrial Engineering 43(1-2):375-92. Retrieved (http://linkinghub.elsevier.com/retrieve/pii/ S0360835202000803).

Lee, Z. W., D. N. Ford, and N. Joglekar (2007), "Effects of Resource Allocation Policies for Reducing Project Durations : A Systems Modelling Approach." Systems Research and Behavioral Science 566(October 2006):551-66.

Liu, S., K. P. Triantis, and S. Sarangi (2010), “A Framework for Evaluating the Dynamic Impacts of a Congestion Pricing Policy for a Transportation Socioeconomic System." Transportation Research Part A: Policy and Practice 44(8):596608.

Luna-Reyes, L. F., L. J. Black, A. M. Cresswell, and T. A. Pardo (20080, "Knowledge Sharing and Trust in Collaborative Requirements Analysis." System Dynamics Review 23(3):265-97.

Lyneis, J. M., and D. N. Ford (2007), "System Dynamics Applied to Project Management: A Survey, Assessment, and Directions for Future Research." System Dynamics Review 23(2-3):157-89. Retrieved (http://doi.wiley.com/10.1002/ sdr.377)

Macal, C. M. (2010), "To Agent-Based Simulation from System Dynamics." Pp. 371-82 in Proceedings of the 2010 Winter Simulation Conference, edited by B Johansson, S Jain, J Montoya-Torres, J Hugan, and E Yücesan.

Maidstone, R. (2012), "Discrete Event Simulation, System Dynamics and Agent Based Simulation : Discussion and Comparison." System 1-6.

North, M. J., and C. M. Macal (2007), Managing Business Complexity: Discovering Strategic Solutions with AgentBased Modeling and Simulation. Oxford University Press: New York.

Rabelo, L., M. Helal, A. Jones, and H. S. Min (2005), "Enterprise Simulation: A Hybrid System Approach." International Journal of Computer Integrated Manufacturing 18(6):498-508. Retrieved (http://www.tandfonline.com/ doi/abs/10.1080/09511920400030138).

Richardson, G. (1991), Feedback Thought in Social Science and Systems Theory. Philadelphia: University of Pennsylvania Press.

Roberts, E. (1978), Managerial Applications of System Dynaimcs. Cambridge, MA: Productivity Press.

Selznick, P. (1948), Foundations of Th Theory of Organizations'. ASR.
Shannon, R. E. (1975), Systems Simulation: The Art and Science. PrenticeHall, Englewood.

Siebers, P. O., C. M. Macal, J. Garnett, D. Buxton, and M. Pidd (2010), "Discrete-Event Simulation Is Dead, Long Live Agent-Based Simulation!" Journal of Simulation 4(3):20410. Retrieved (http://www.palgrave-journals.com/doifinder/10.1057/jos.2010.14).

Sterman, J., G. Richardson, and P. Davidsen (1998), “Modelling the Estimation of Petroleum Resources in the United States." Technological Forecasting and Social Change. 33(3):219-49.

Sumari, S., R. Ibrahim, N. H. Zakaria, and A. H. A. Hamid (2013), "Comparing Three Simulation Model Using Taxonomy: System Dynamic Simulation, Discrete Event Simulation and Agent Based Simulation." International Journal of Management Excellence 1(3):54-59. Retrieved (http://ijmeonline.com/index.php/ijme/article/view/1300000009).

Tako, A., and S. Robinson (2012), "The Application of Discrete Event Simulation and System Dynamics in the Logistics and Supply Chain Context." Decision Support Systems 52(4):802-15. Retrieved (http://linkinghub.elsevier.com/ retrieve/pii/S0167923611002211).

Trist, E. L., and K. W. Bamforth (1951), Some Social and Psicological Consequences of the Long Wall Method of CoalGetting. edited by Human Relations.

Vicsek, T. (2002) "Complexity: The Bigger Picture." Nature 418(6894):131.

Wang, G., and E. a. B. Eltahir (2000), "Ecosystem Dynamics and the Sahel Drought." Geophysical Research Letters 27(6):795-98. Retrieved (http://doi.wiley. com/10.1029/1999GL011089).

Weil, H. (2007), "Application of System Dynamics to Corporate Strategy: An Evolution of Issues and Frameworks." System Dynamics Review 23:137-56.

Williams, T., F. Ackermann, and C. Eden (2003), "Structuring a Delay and Disruption Claim: An Application of CauseMapping and System Dynamics." European Journal of Operational Research 148(1):192-204. 